\title{
Competitive Ring Expansion of Azetidines into Pyrrolidines and/or Azepanes
}

Bruno Drouillat, ${ }^{1, *}$ Igor V. Dorogan, ${ }^{2}$ Mikhail Kletskii, ${ }^{3}$ Oleg N. Burov, ${ }^{3}$ and François
Couty $^{1, *}$

${ }^{1}$ Institut Lavoisier de Versailles, UMR 8180. Université de Versailles St-Quentin-enYvelines, Université Paris Saclay - 45, av. des Etats-Unis, 78035 Versailles Cedex, France, Fax:+33 (0) 1392544 52, E-mail: couty@,chimie.uvsq.fr, bruno.drouillat@uvsq.fr.

${ }^{2}$ Institute of Physical and Organic Chemistry, Southern Federal University, 194/2 Stachka Ave., 344090 Rostov-on-Don, Russian Federation

${ }^{3}$ Department of Chemistry, Southern Federal University, 7, Zorge St., 344090, Rostov-onDon, Russian Federation.

\section{Supporting Information}

\section{$\underline{\text { Content }}$}

${ }^{1} \mathrm{H}(300 \mathrm{MHz})$ and ${ }^{13} \mathrm{C}(75 \mathrm{MHz}) \mathrm{NMR}$ spectra in $\mathrm{CDCl}_{3}$ of all synthesized products $\mathrm{S} 2-\mathrm{S} 29$ 

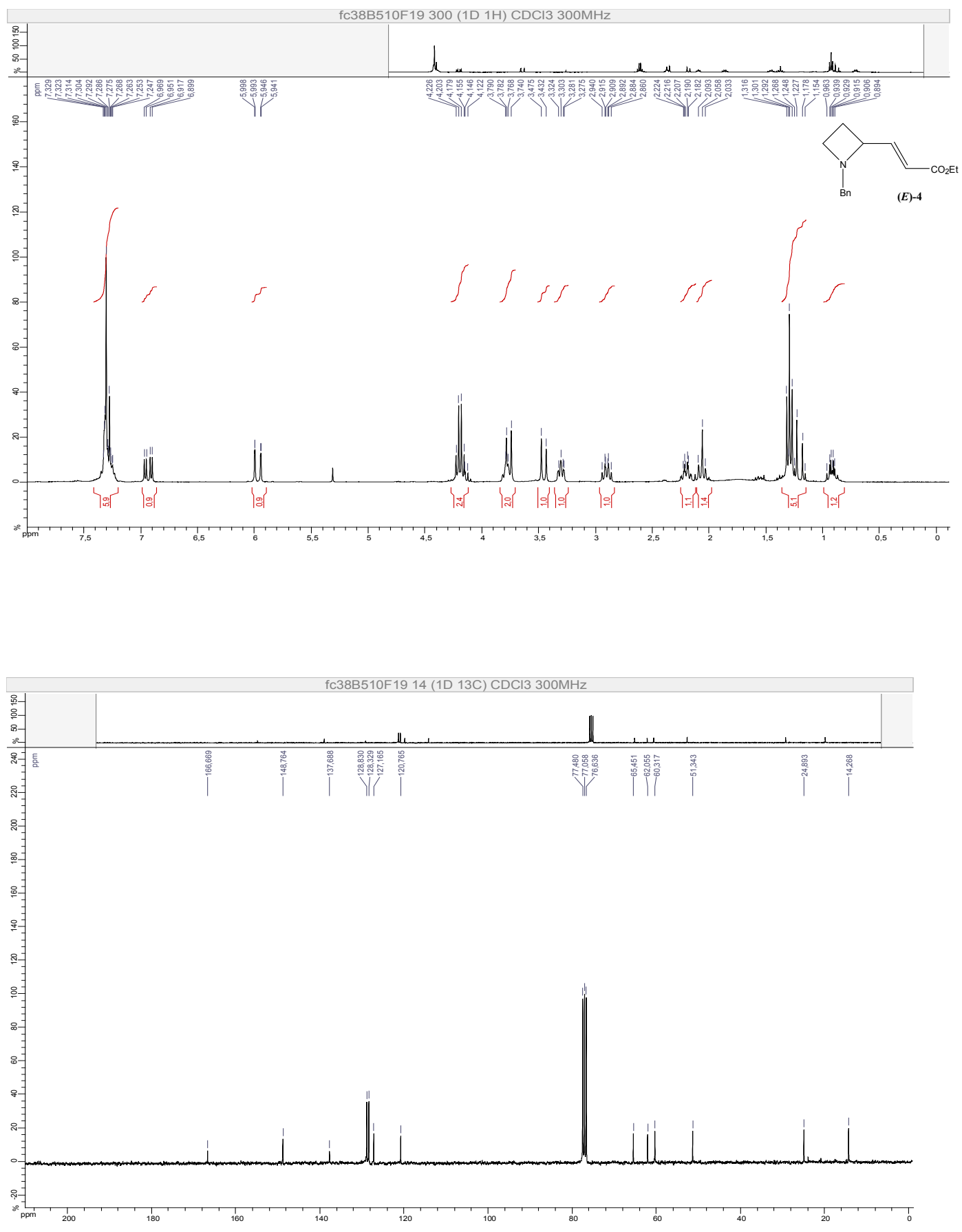

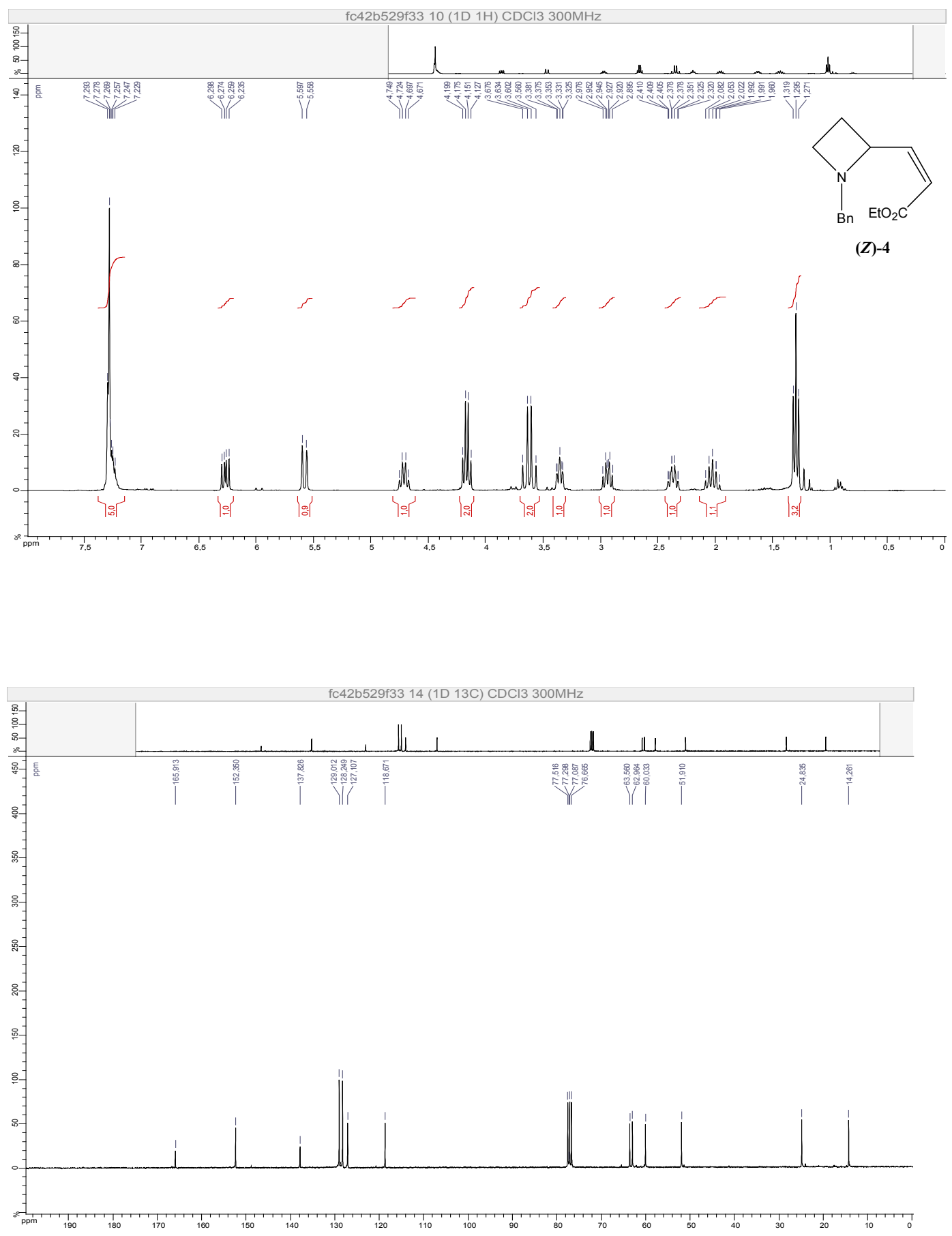

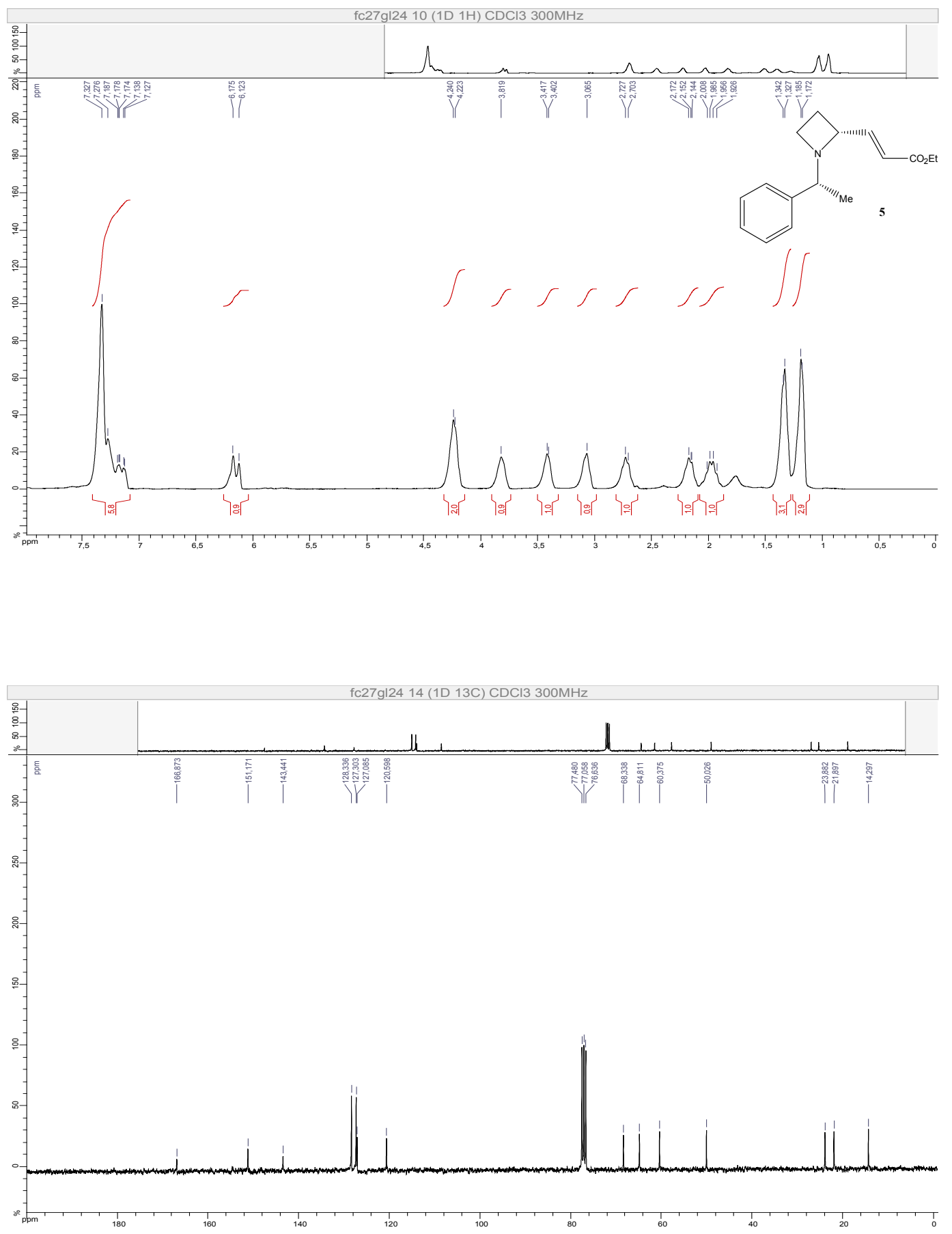

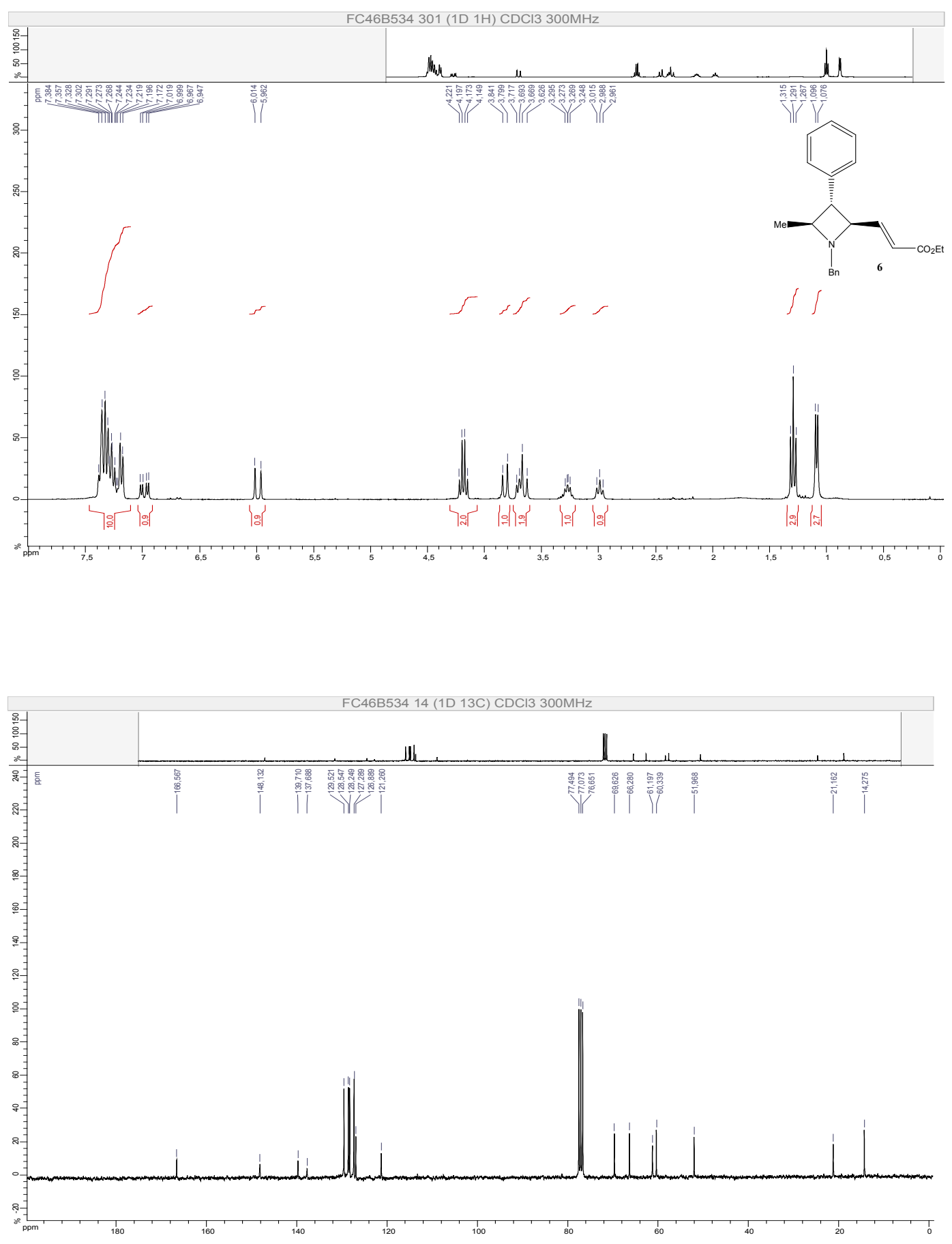

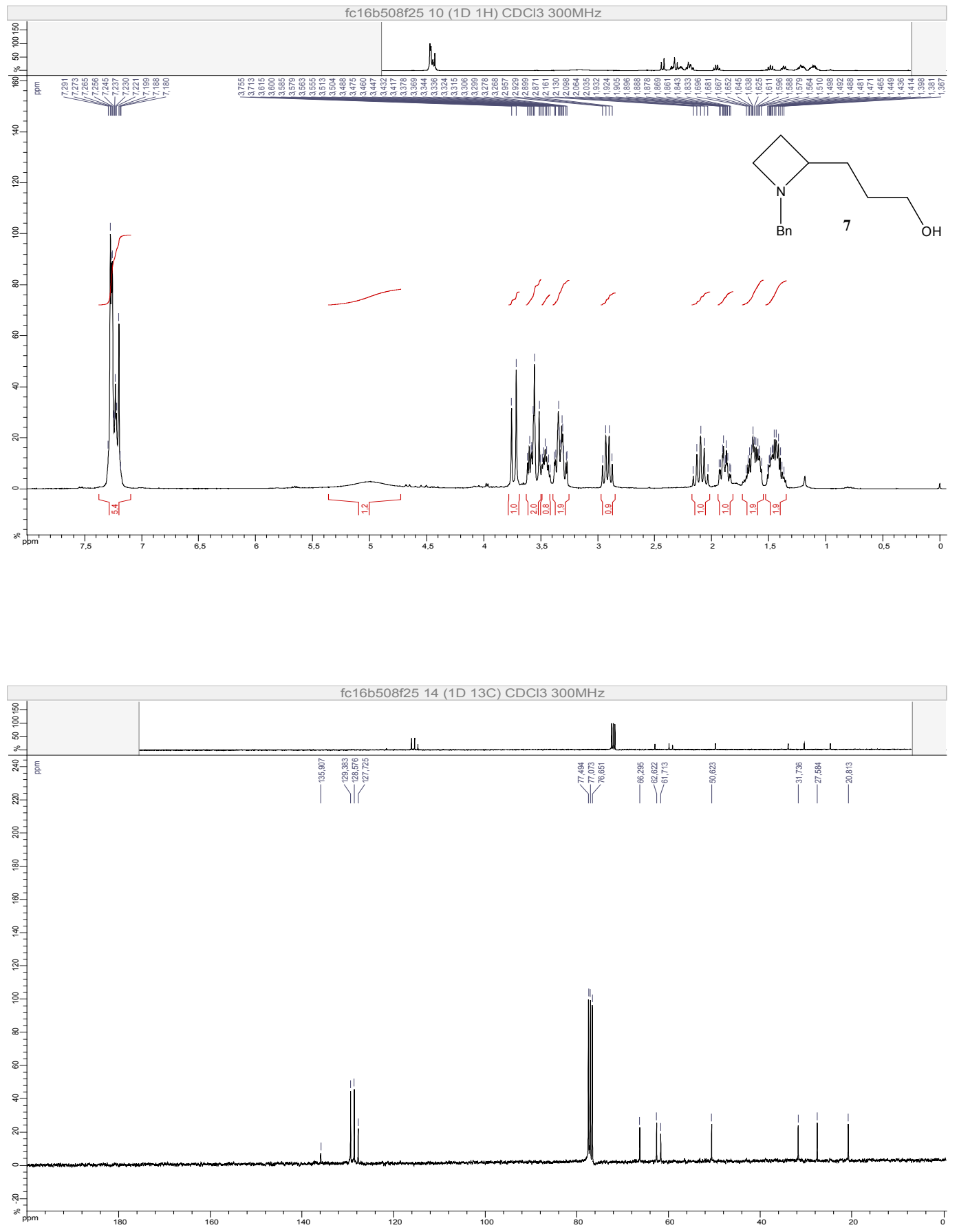

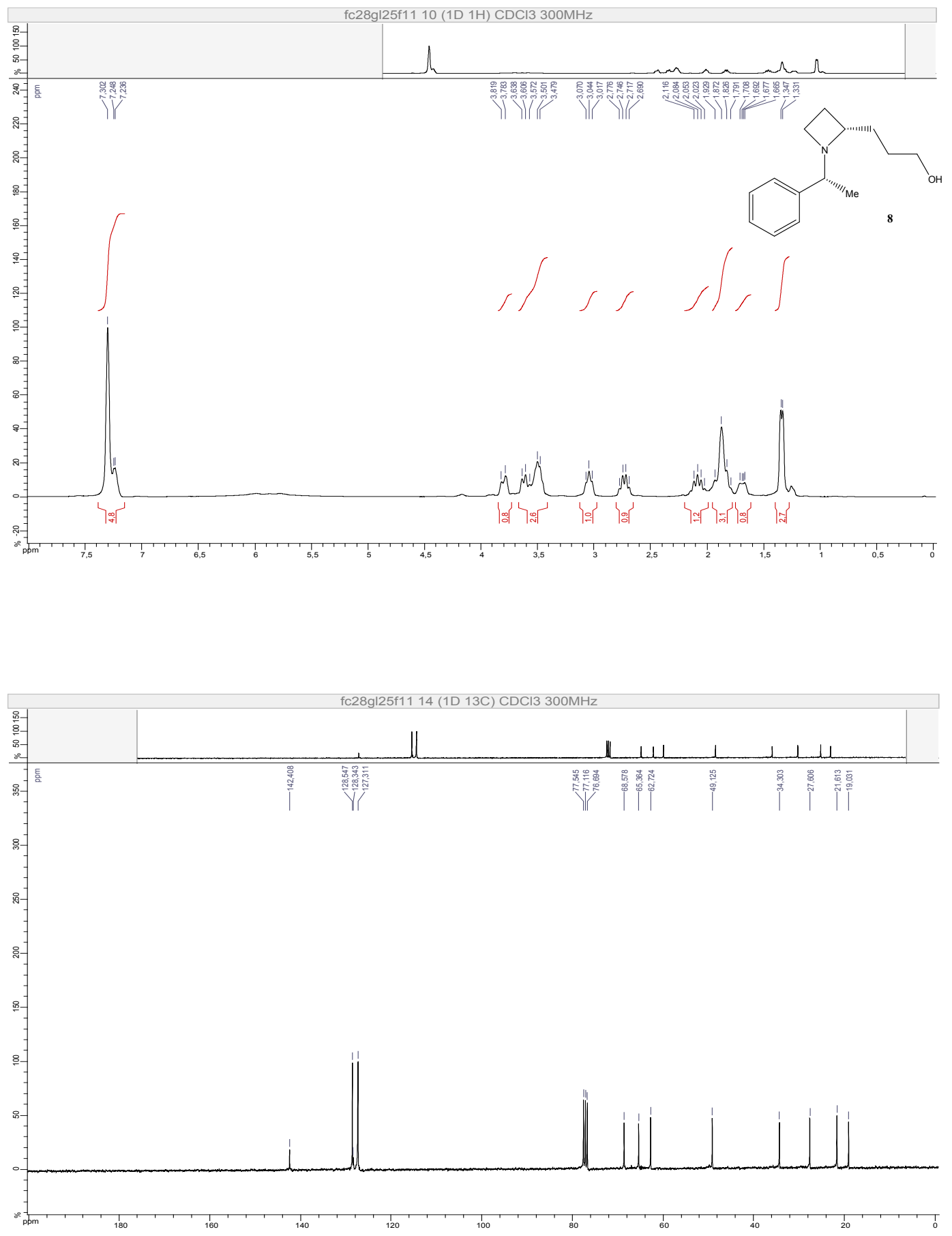

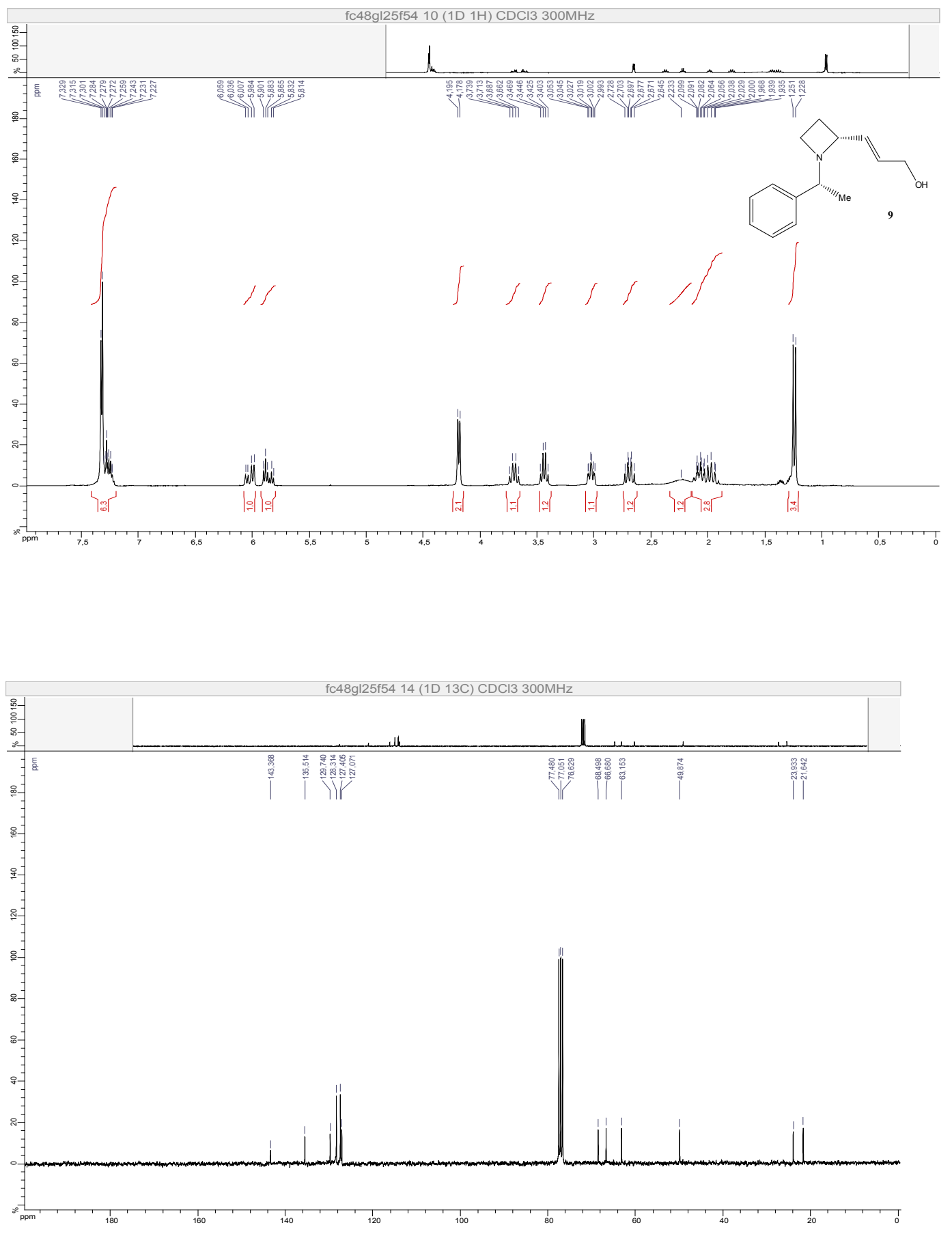

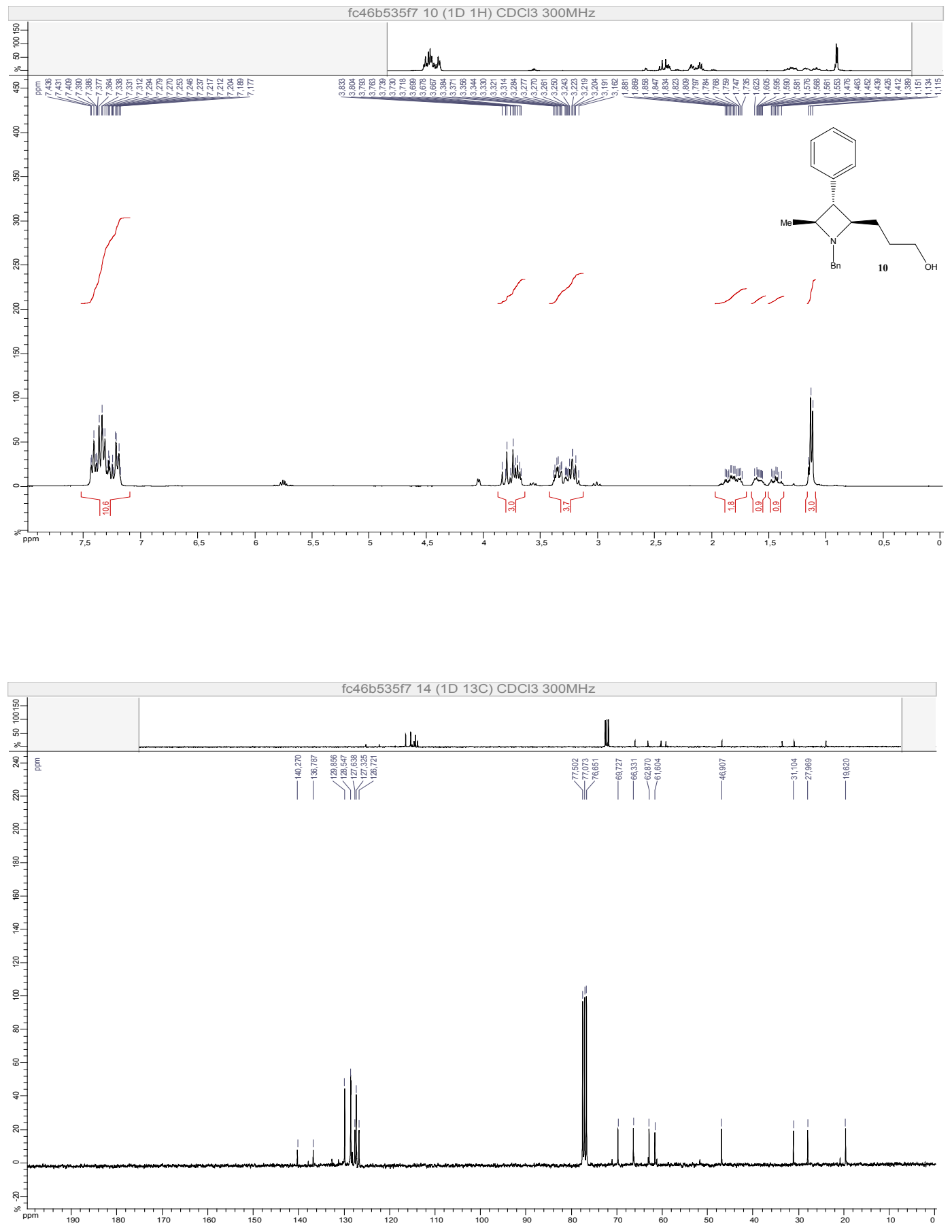

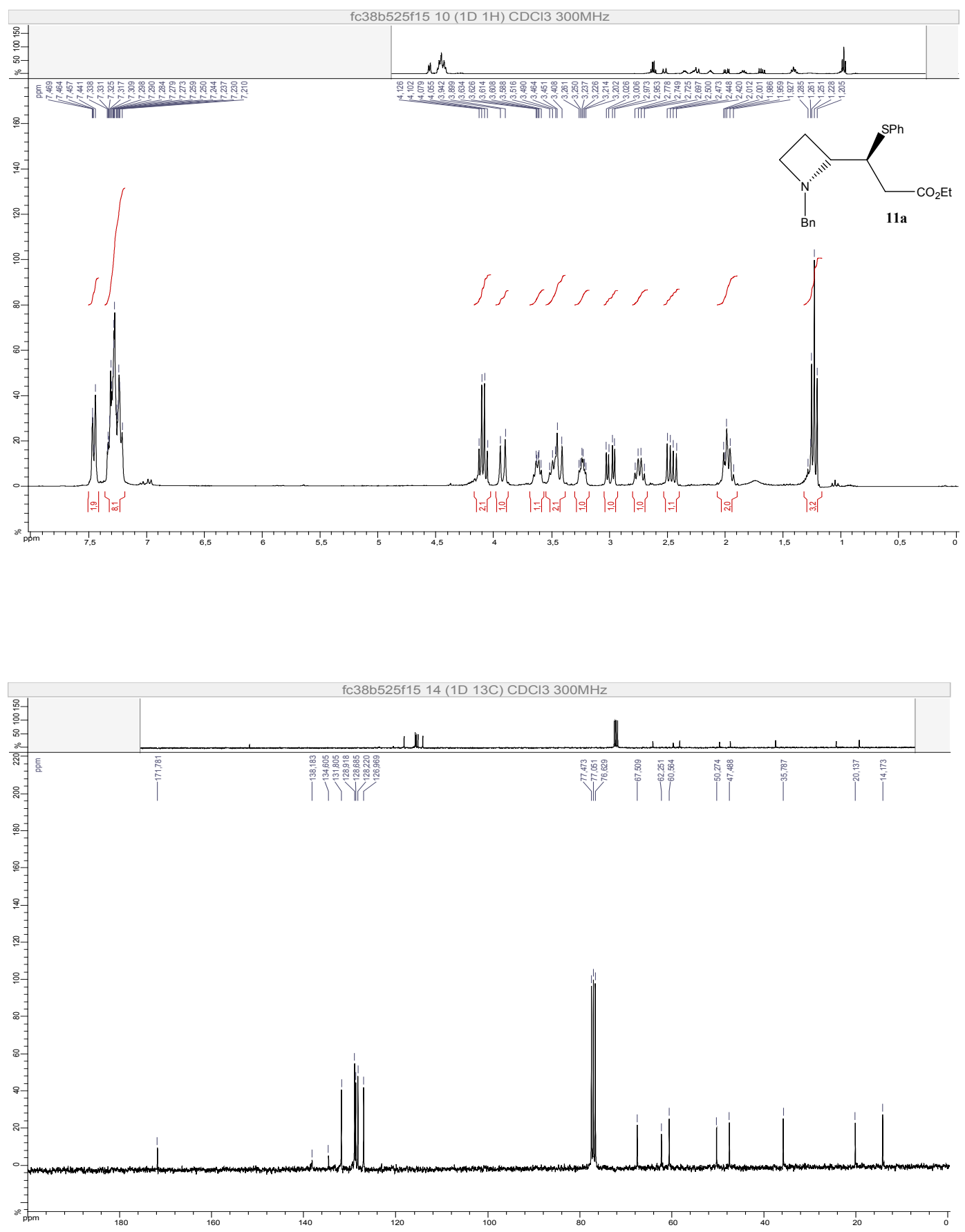

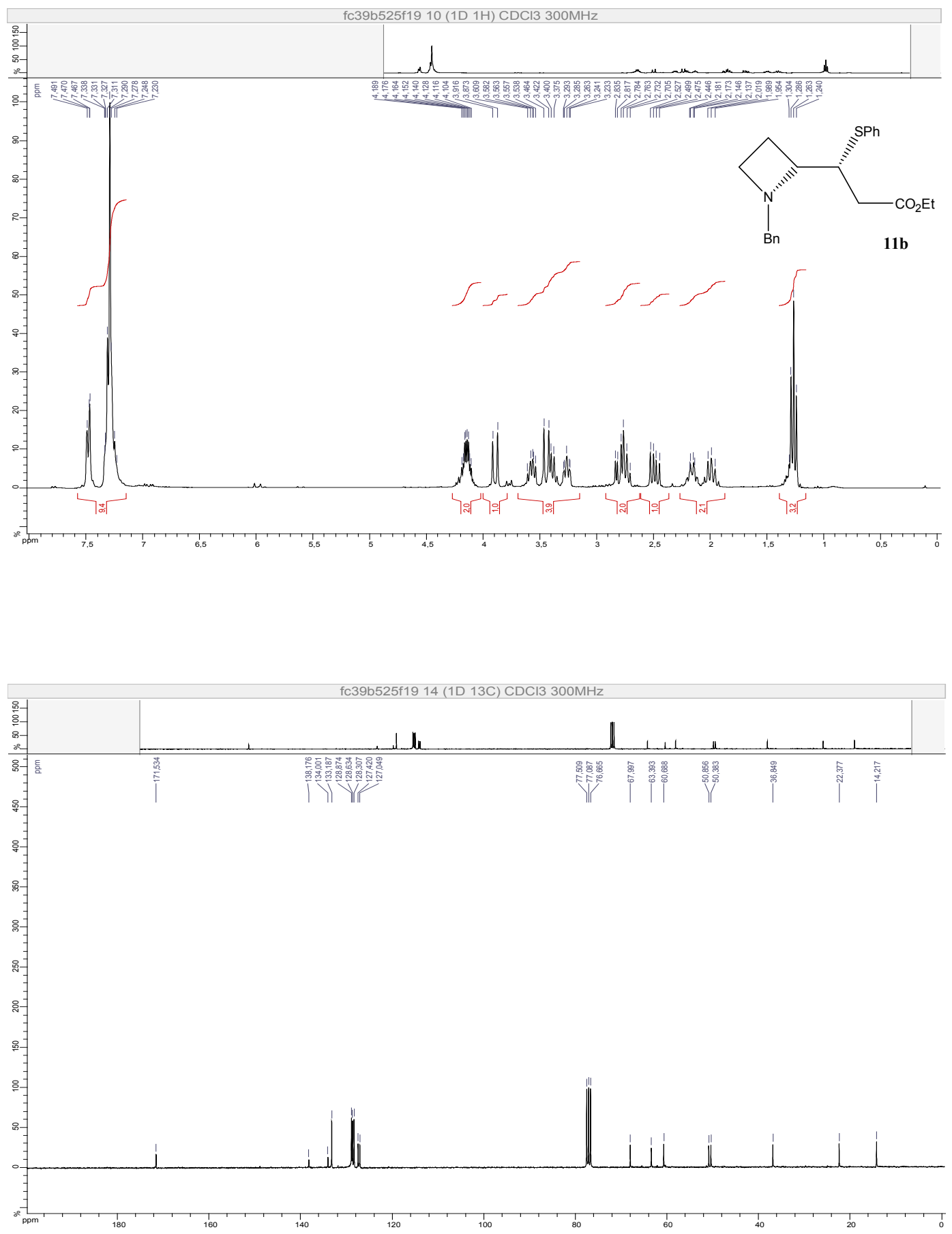

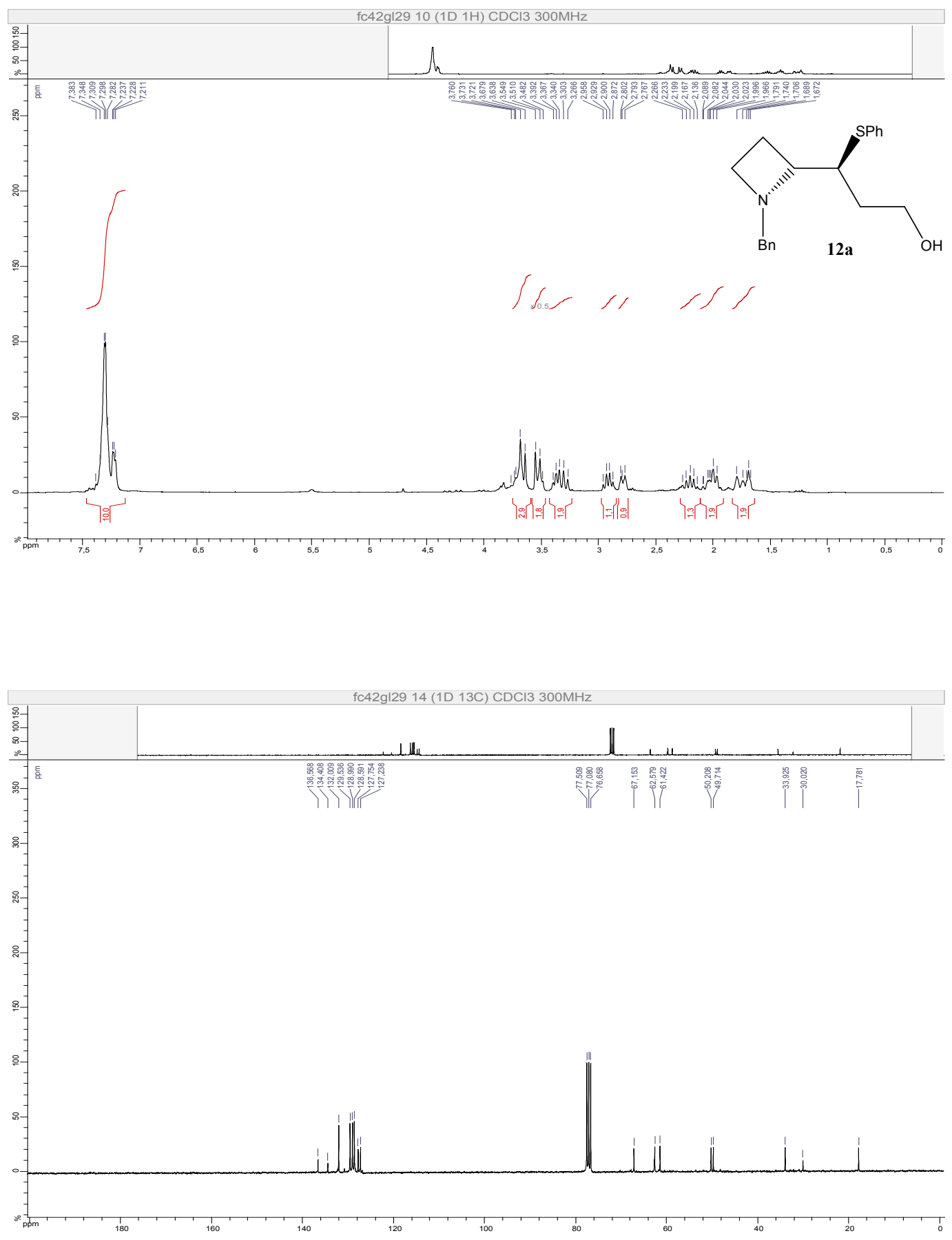

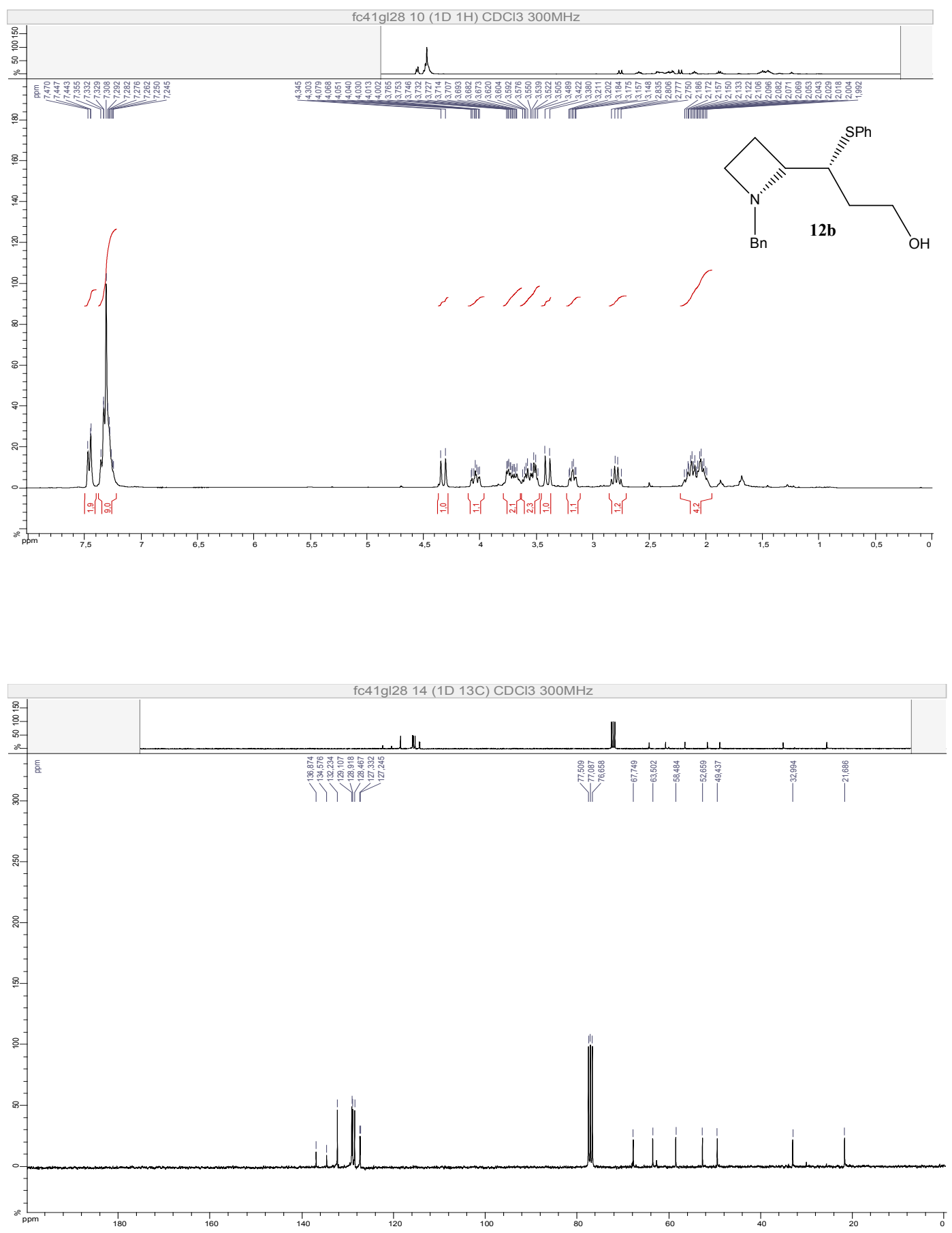

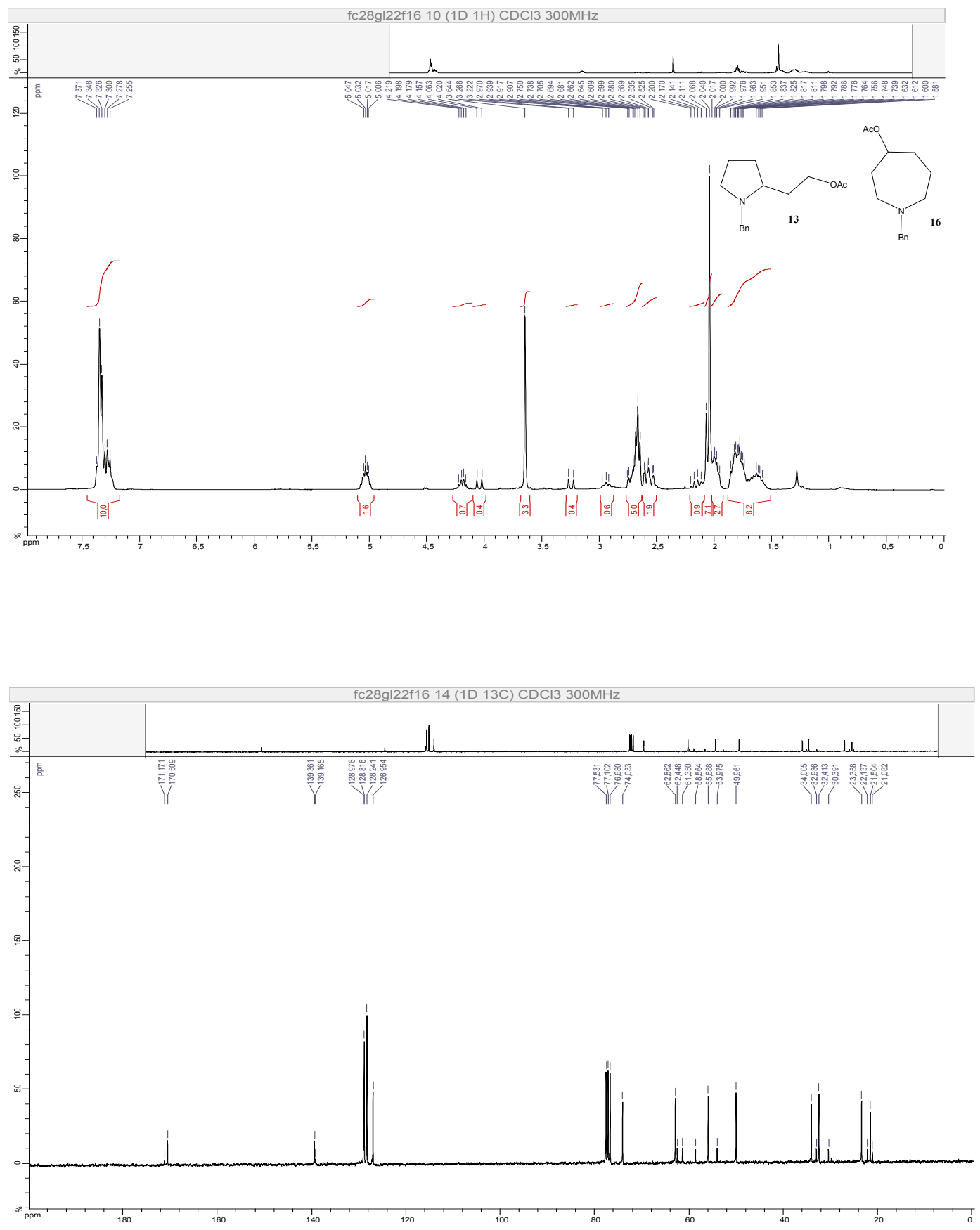

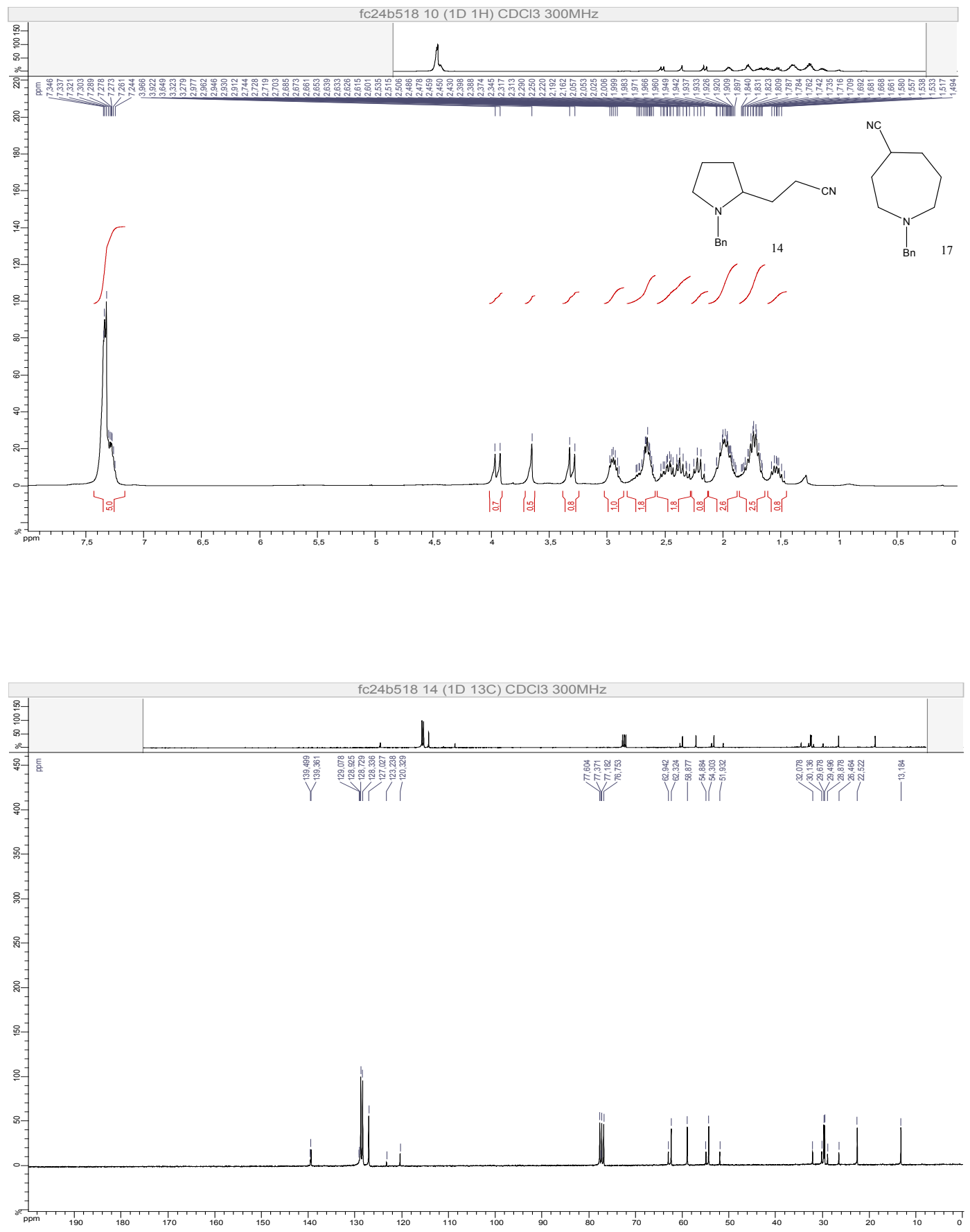

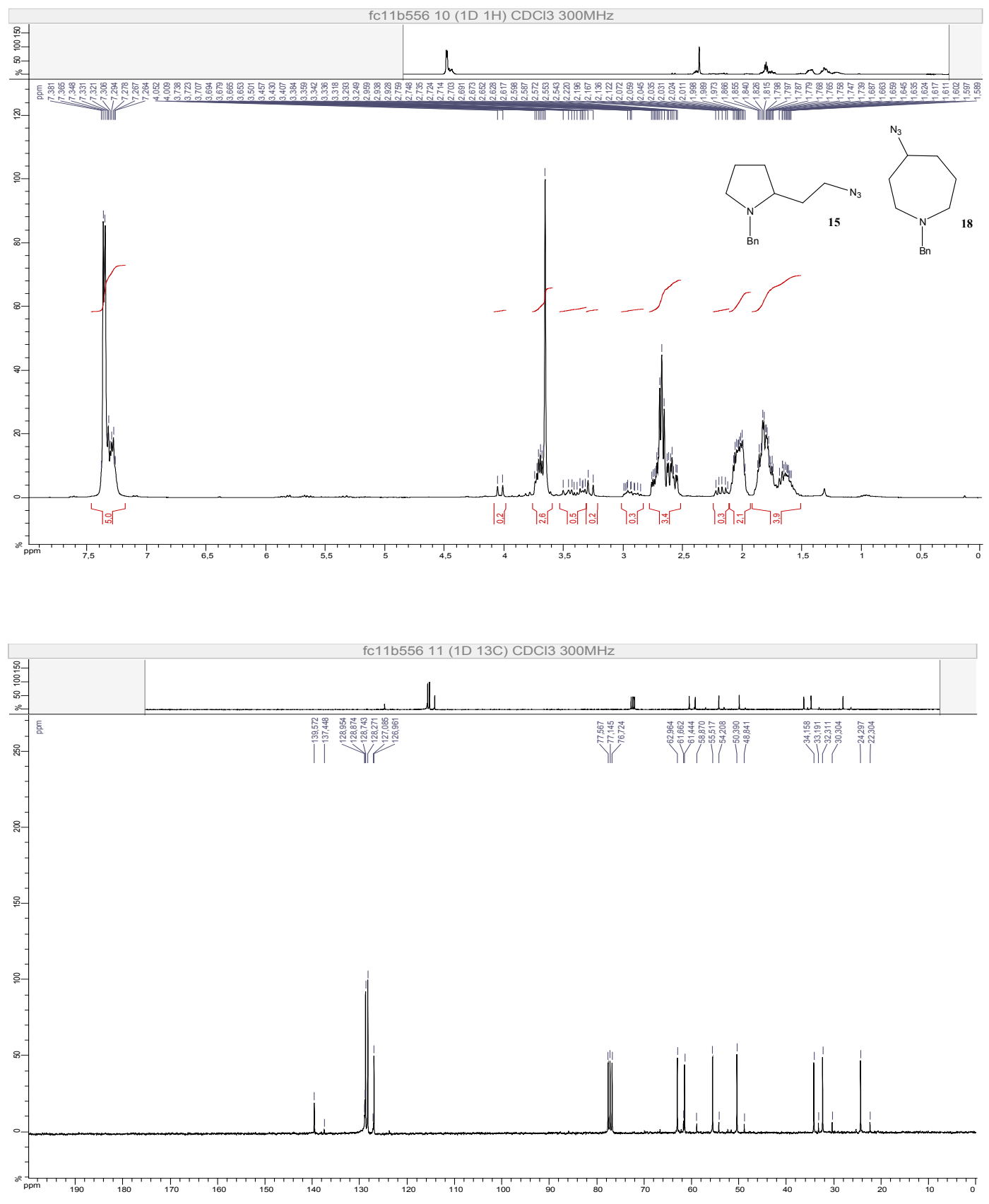

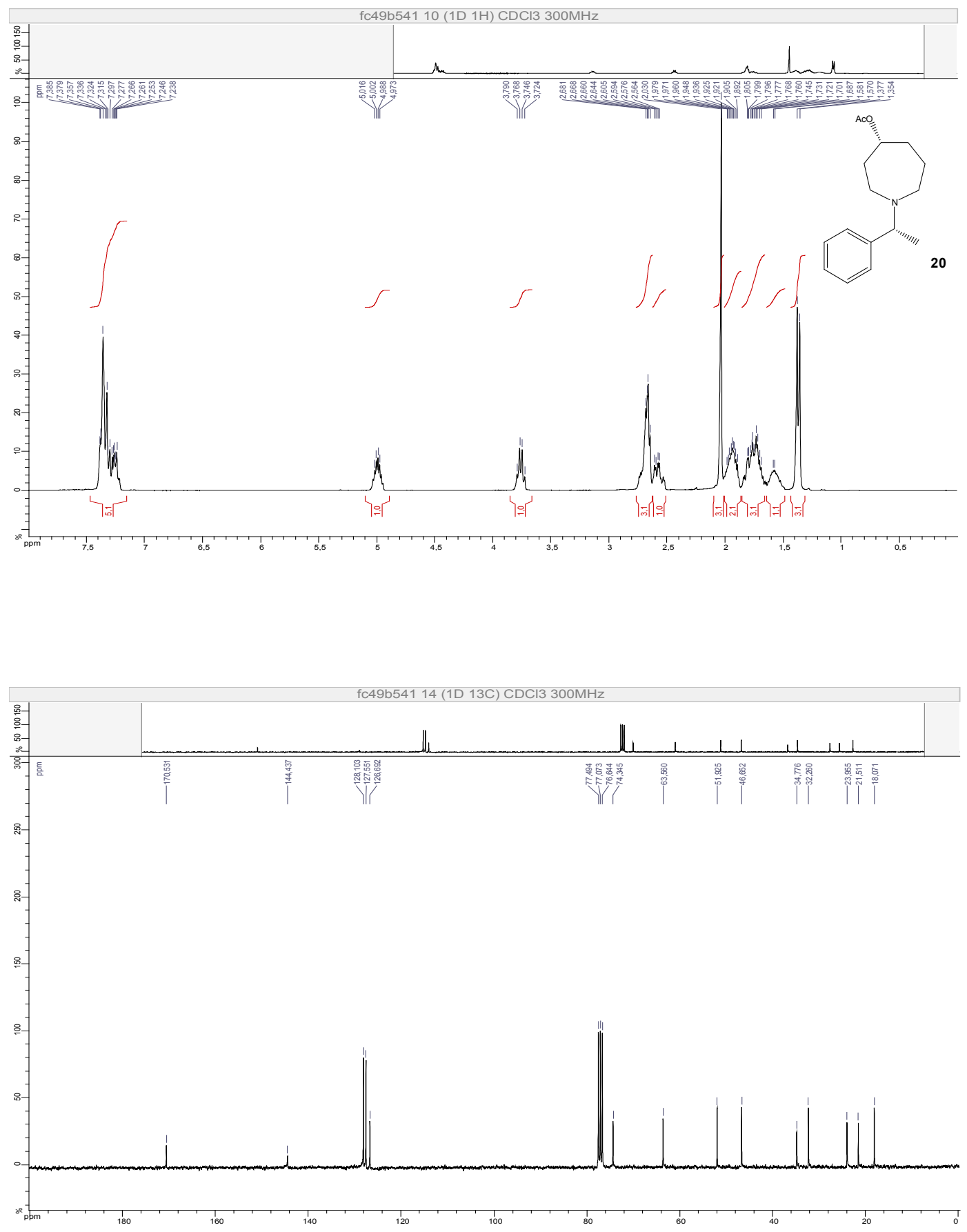

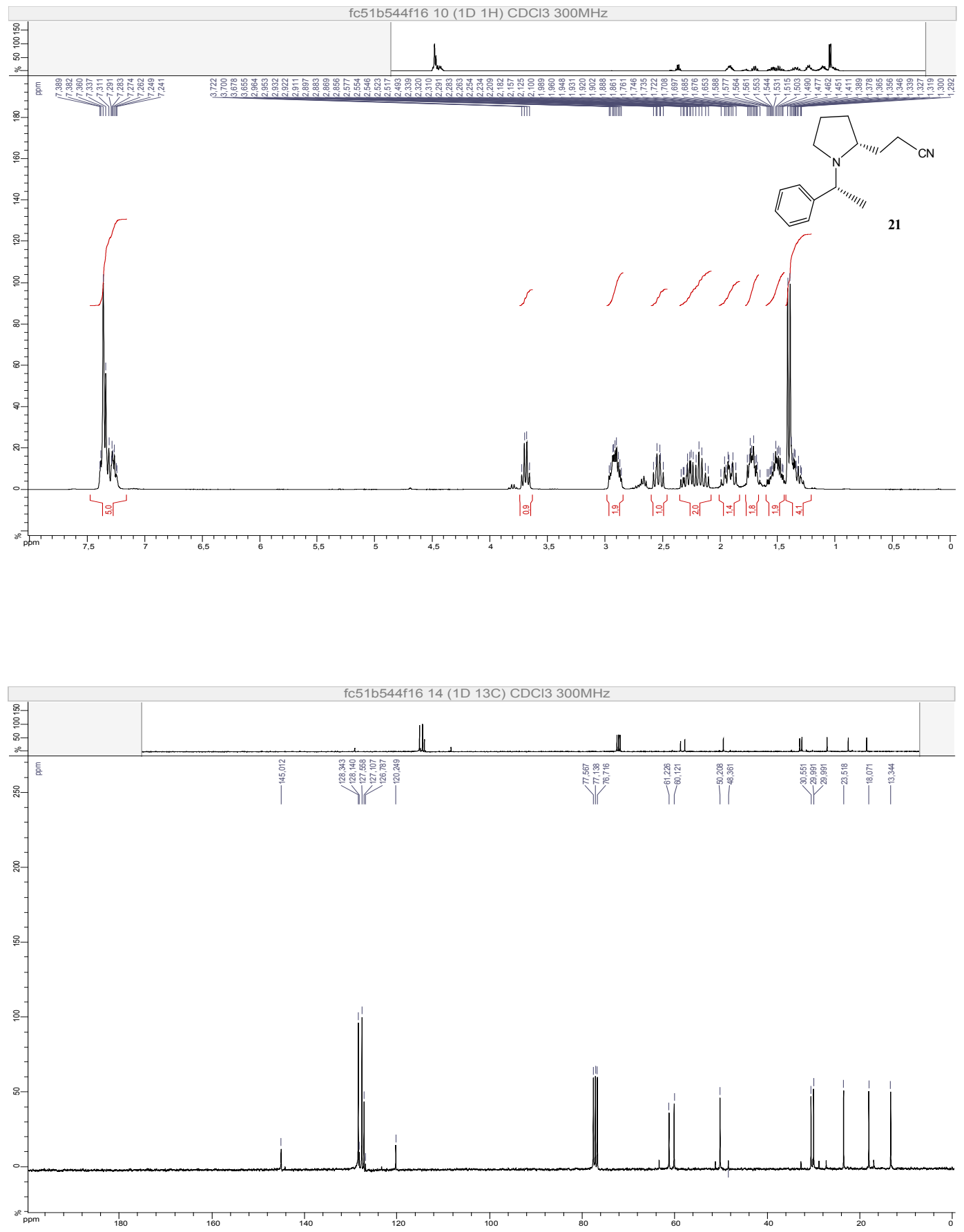

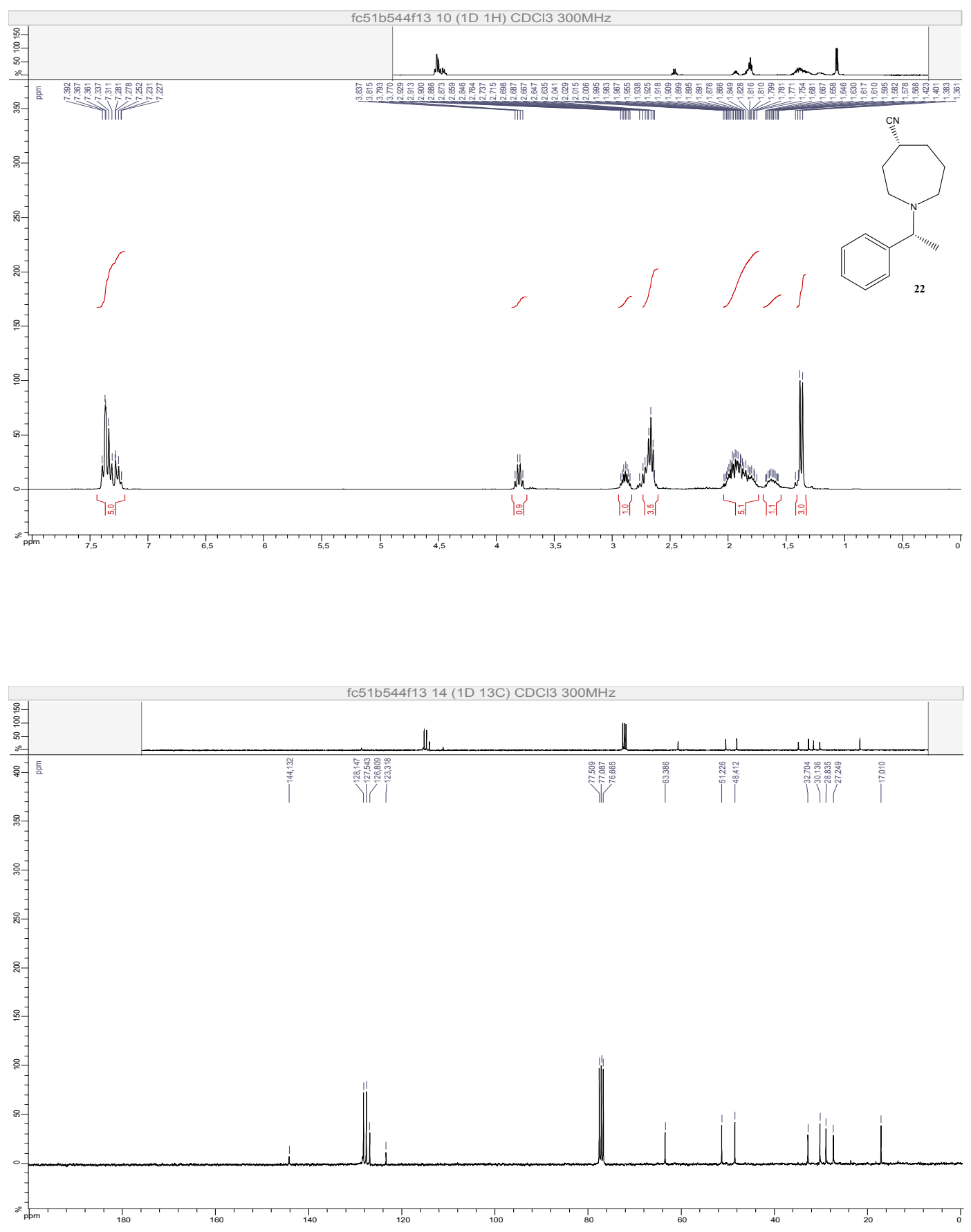

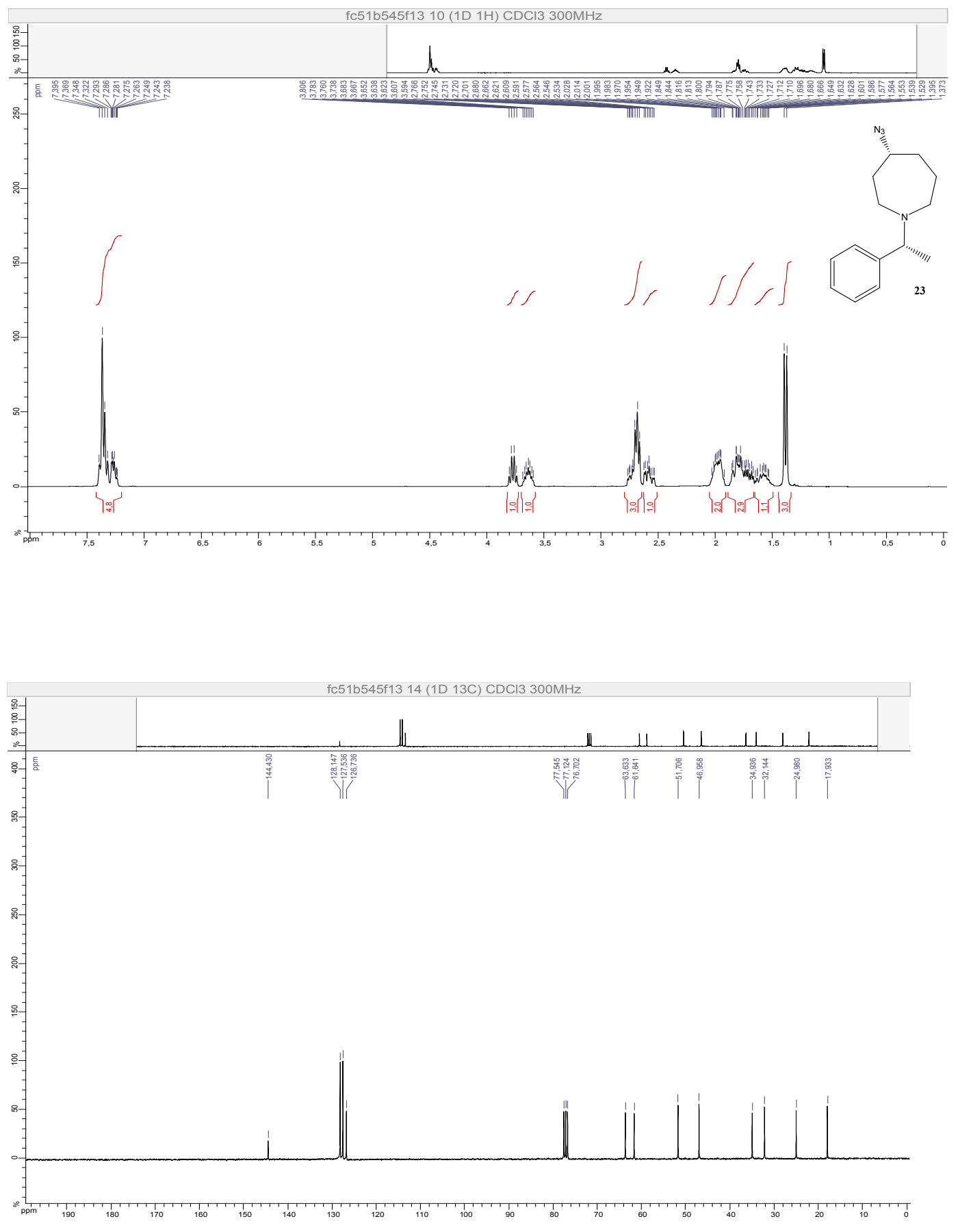

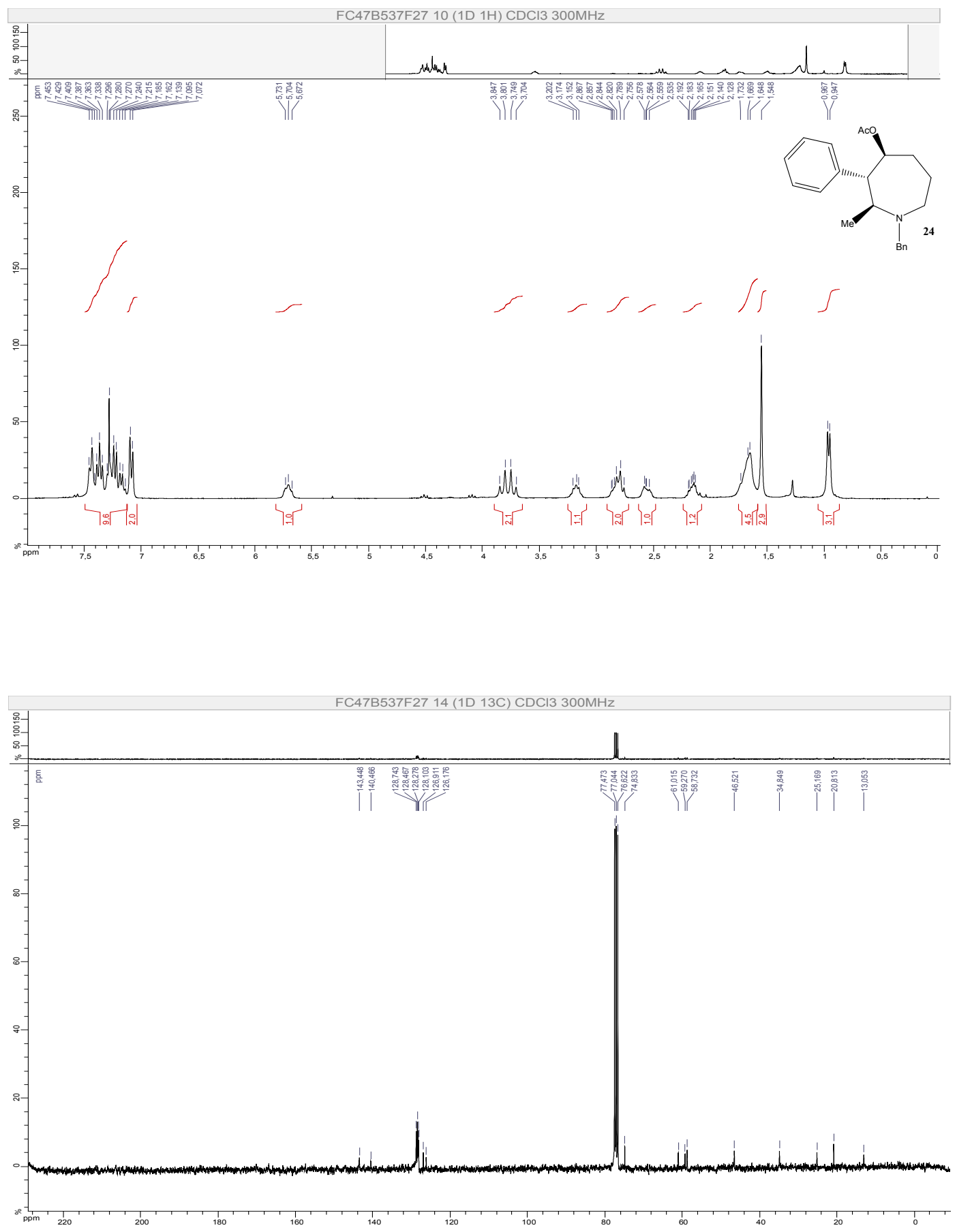

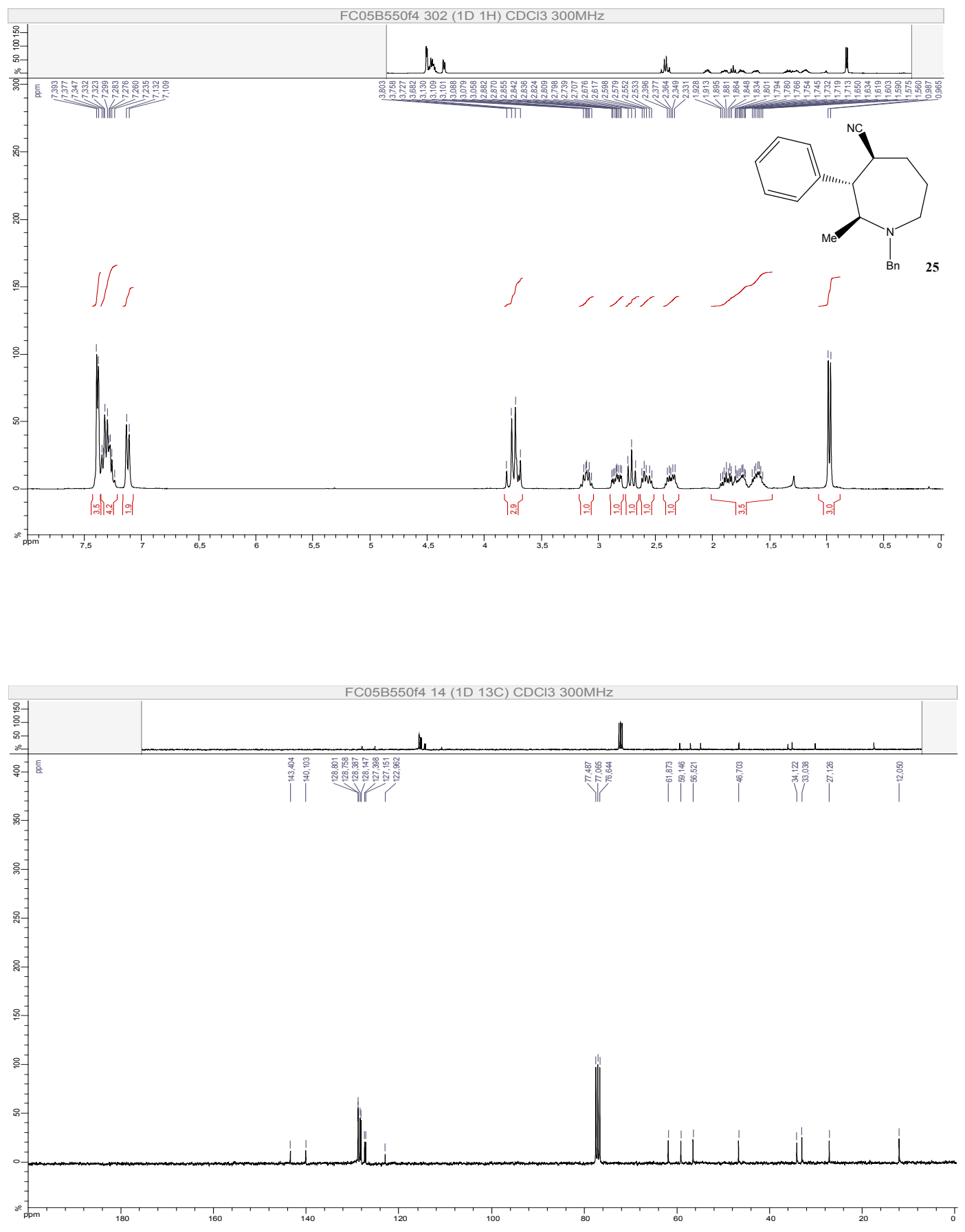

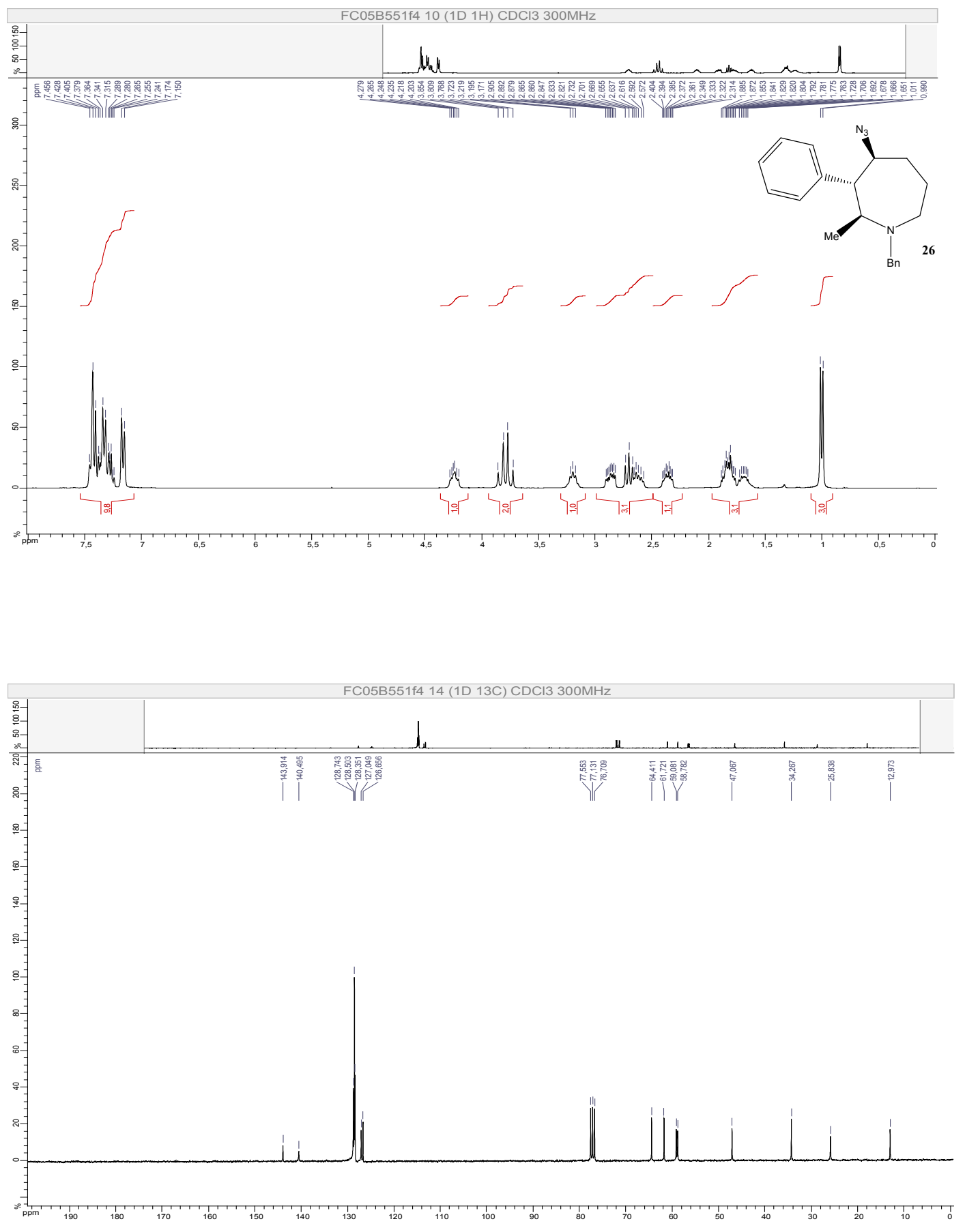

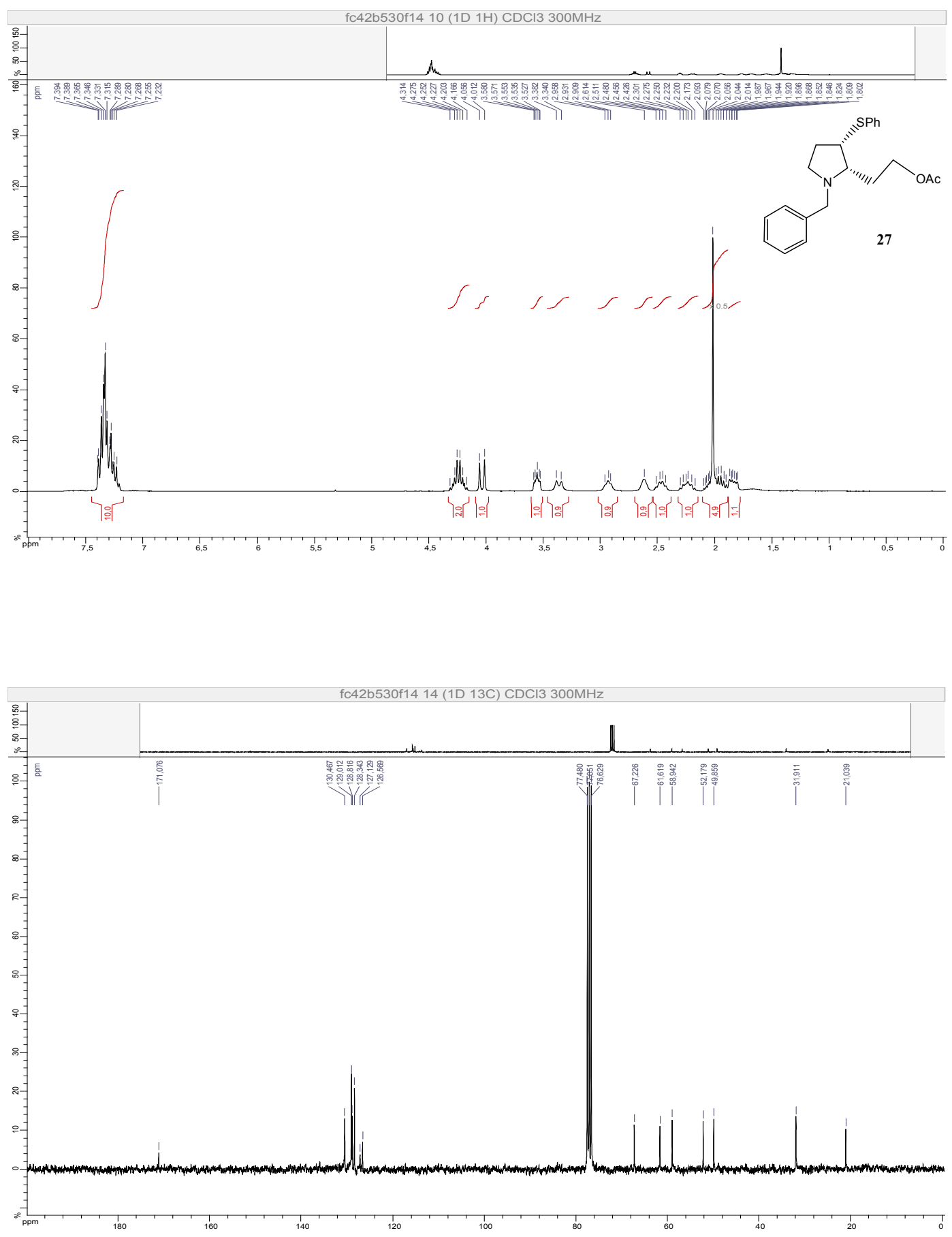

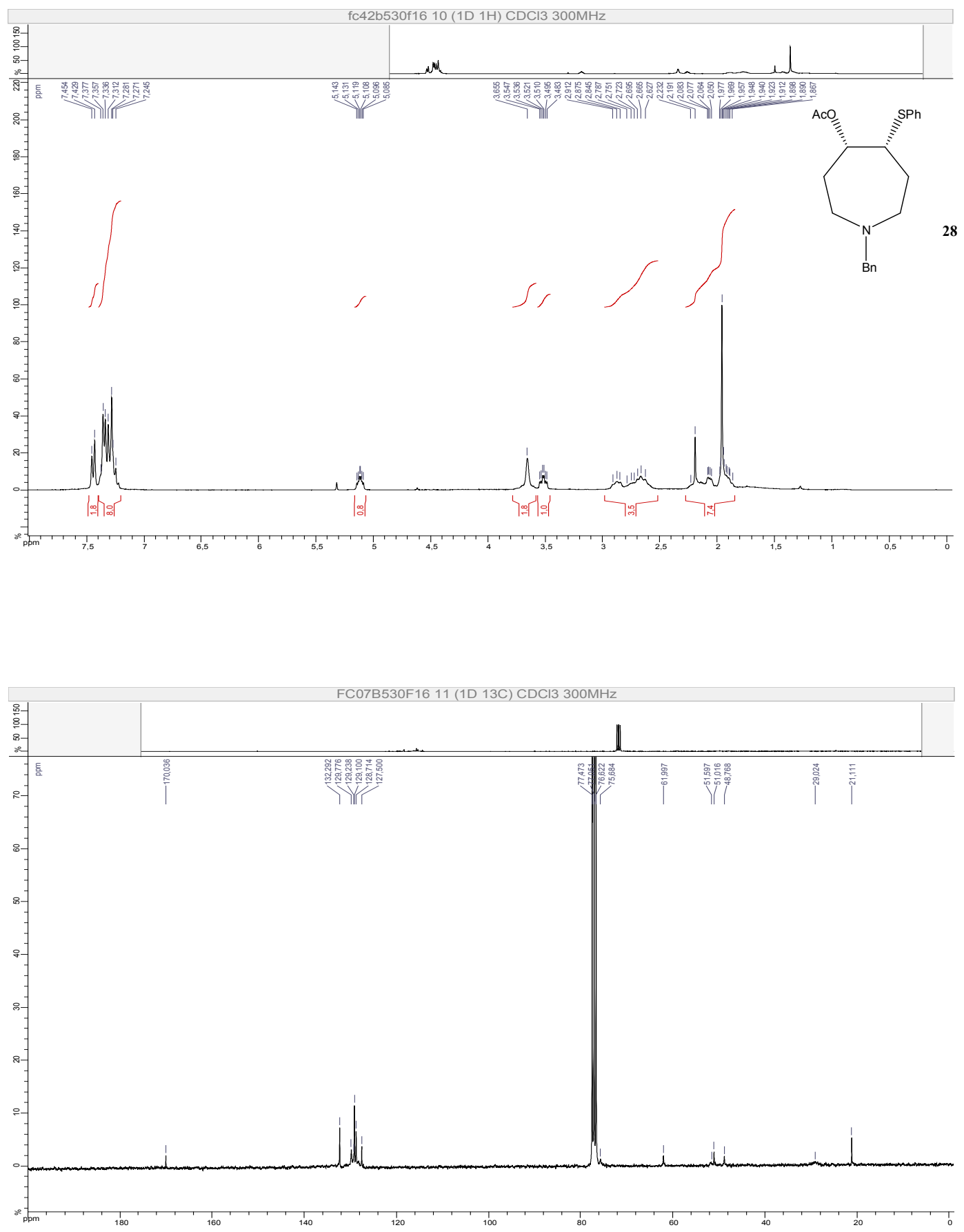

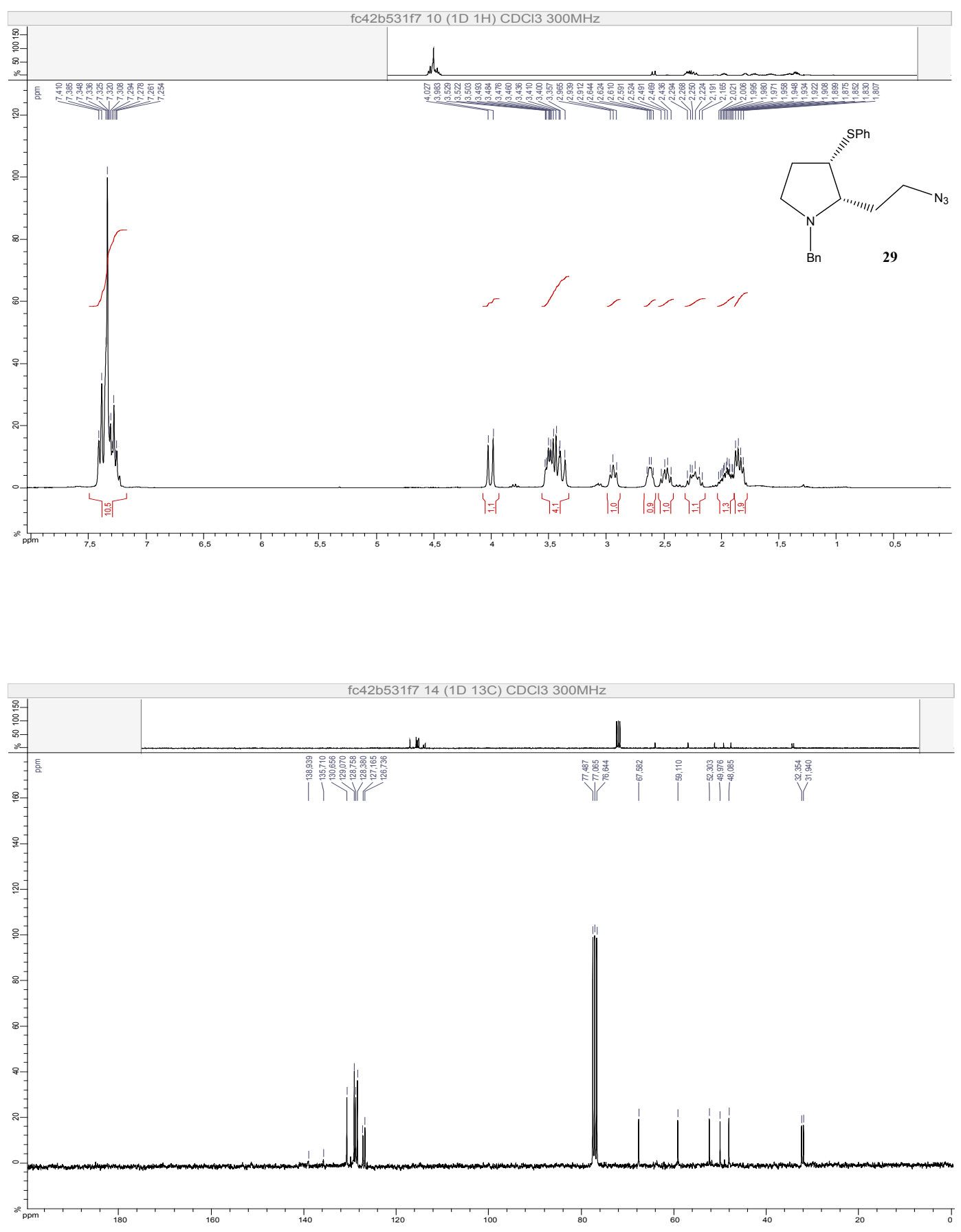

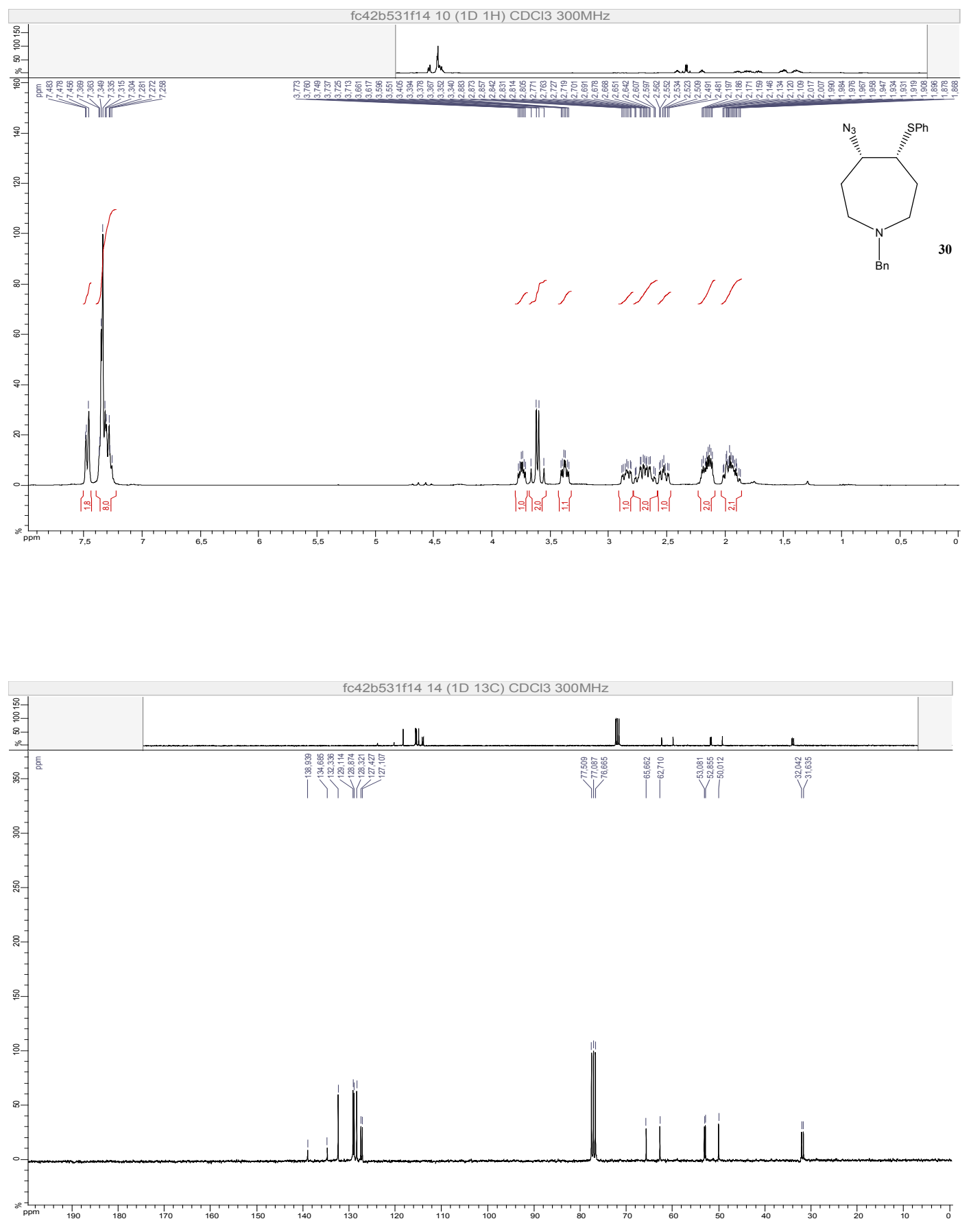

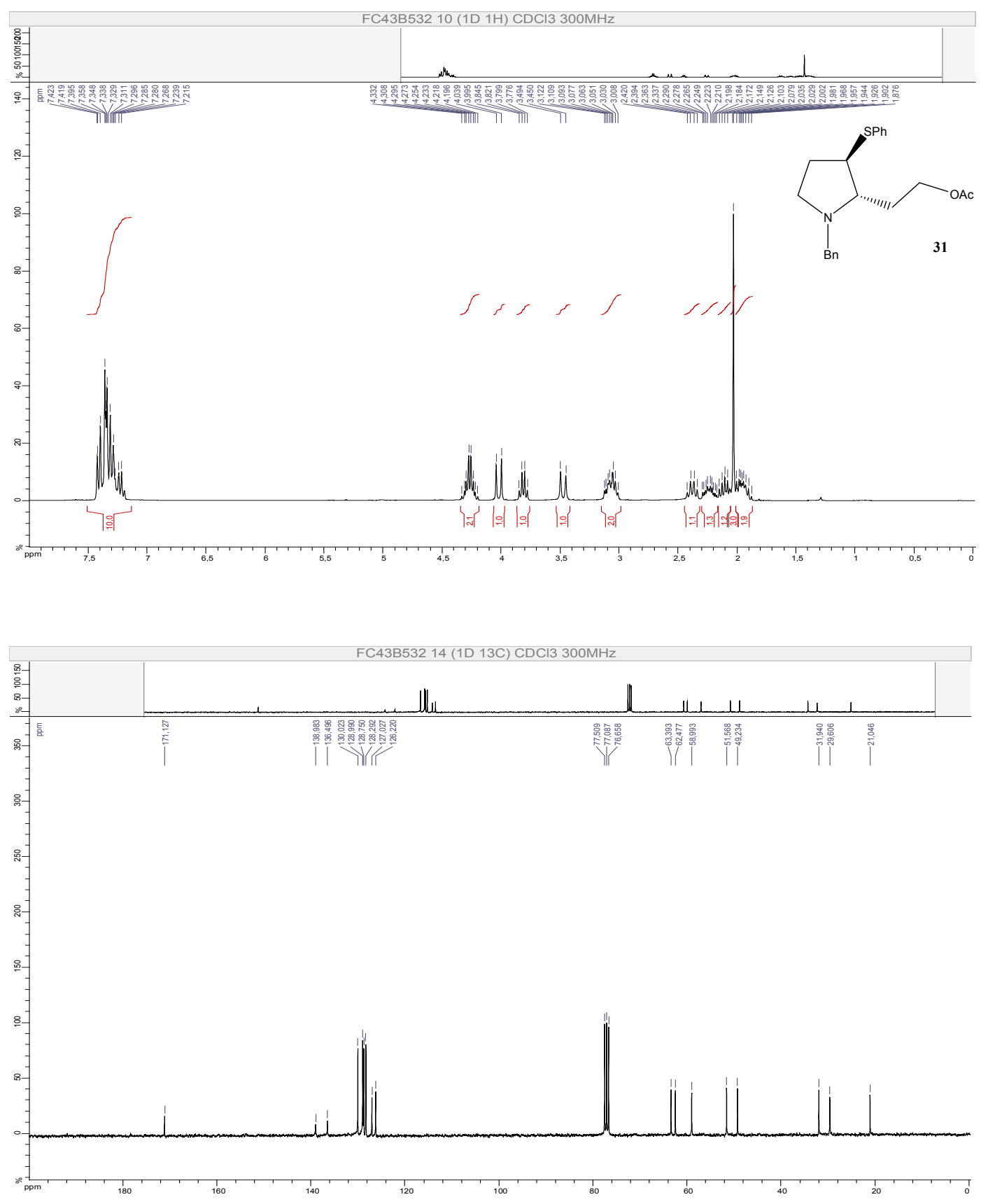

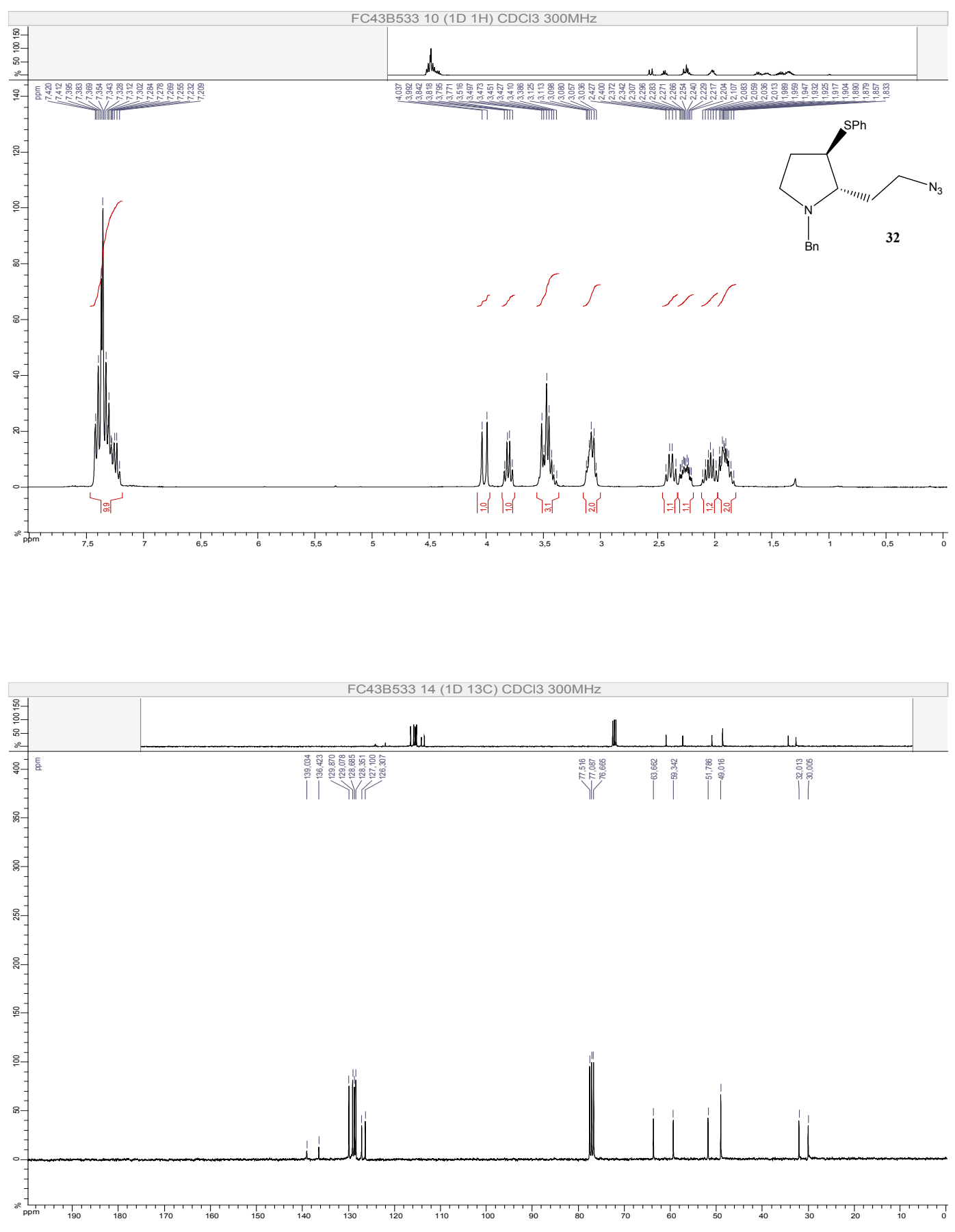